\title{
Stocks, Bonds and Foreign Exchange Inter-linkages: A Market Micro-structure Perspective in Kenya
}

\author{
Caspah Lidiema*, Irungu Macharia \\ Department of Economics, Accounts, \& Finance, Jomo Kenyatta University of Agriculture and Technology \\ *Corresponding author: caspahlidiema@gmail.com
}

\begin{abstract}
This paper examined Market Micro-structure interrelations between Stocks, Bonds and Foreign Exchange Markets. The Study analyzed both unconditional correlation, dynamic relationship and volatility spillovers effects between the markets. The analysis used the asymmetric dynamic conditional correlation (aDCC) using Exponential Generalized Autoregressive Conditional Heteroskedastic model (EGARCH). Using monthly data from Kenyan market during the period January 2004 - June 2017, results indicate that there is significant market interactions and interlinkages and existence time varying variance correlation between any bivariate set in the three markets in Kenya. While, the conditional correlations are positive, the unconditional correlation reveal, a negative correlation between Foreign exchange markets and the Bonds as well as stocks. The study proposes policy makers like the government through treasury, capital markets authority (CMA) and Nairobi securities exchange (NSE) to encourage more Kenyan investors to invest in bond market by marketing the bond market through educational forums, conferences. For the Proposal to take effect, appropriate authorities should stabilize the Kenyan currency through monetary interventions.
\end{abstract}

Keywords: EGARCH, volatility, stocks, bonds, foreign exchange

Cite This Article: Caspah Lidiema, and Irungu Macharia, "Stocks, Bonds and Foreign Exchange Inter-linkages: A Market Micro-structure Perspective in Kenya.” Journal of Finance and Economics, vol. 5, no. 6 (2017): 290-299. doi: 10.12691/jfe-5-6-5.

\section{Introduction}

\subsection{Background of the Study}

Most financial markets (Capital Markets, Insurance, Banking and pension funds) in any part of the world have a very close relationship and as such maintain great synergies rather than tradeoffs. Basically, this means that financial markets do not trade or operate in isolation. The synergies have resulted to strengthening of economies. The inter-markets relationships have shown the importance of giving positive direction of the economy. However, the disadvantage of close relationships may lead to problems in transmissions either directly or indirectly through monetary policies or failure of one or more markets.

\subsection{Stocks \& Bonds}

The correlation between stocks and bonds is still giving researchers a wide berth in coming to a consensus. It's not clear as to whether stocks and bonds move in the move in the opposite direction hence inverse relationship (proposition 1) or if they same direction hence direct relationship (proposition 2) Proponents of proposition 1 have a general feeling that equity markets rise when the economy is either doing well. This means that most companies are making good returns on assets/ investments hence leading to better share valuations. But on the other hand, improved profits can also lead to increased inflation which then causes bond prices to fall. Inflation leads monetary policy adjustments by trying to bring inflation down by increasing interest rates in the market. In effect again, increasing interest rates means it's expensive for companies that wish to raise capital from the market through issuance of bonds. This therefore slows down the bond market due to reduced yields. However, when the economy is on slow down like, the equity prices fall and this leads to investors seeking a riskless asset like in bonds.

Proponents of proposition 1 belief that holding both asset classes can help manage risk through asset allocation mechanism. However, the movement in either assets in same or opposite direction could be attributed to several factors including monetary policy, or government fiscal policy. For instance, if government wishes to finance budget deficits, it could borrow from the markets through issuing bonds with favorable rates of return, this could shift focus of investors from equities to stocks. Several studies that been carried out to check correlation between Stocks and bonds include: Jammazi, et al. [1] and Andersson et al. [2]; Li and Zou [3]; Ahmed and Joher [4]; Rankin and Idil [5]. Fan and Mitchell [6] state that, Equity-bond correlation is not a static number and can either be positive or negative. They argue that there is no economic theory or empirical model that fully captures this dynamism but rather the observed correlation is the 
result of rich and dynamic interaction between several macroeconomic factors.

For instance, in Kenya, bond market at the NSE was significantly vibrant in Quarter 1 of 2017 as compared to the equities market in the period under review. The Capital Markets Authority Quarterly report [7] attributed this to the shift in investor interest from the equities market to the bond markets due to many factors including uncertainties in the markets occasioned by global events and the general elections. In fact, this is supported by Skintzi [8] who believe that investors withdraw capital from both equity and bond markets in times of economic crisis and financial crisis to invest in other classes of assets. However, this is mostly attributed markets of developing countries. For instance, during the Supreme Court ruling on 1st September 2017 on the political standoff following the presidential election, the NSE equity market lost 101B during the month of September 2017 with Market capitalization reducing from 2,478.62 Billion in August to 2,376.69 Billion in September 2017, CMA Bulletin [9]. But as to whether this was due to withdrawal of foreign investors is yet to be established. While investor makes preference and decision on purchasing assets, they evaluate market and economic conditions before deciding in which investment pool they think will offer better returns for the risky taken. As to whether investors are guided by fear and greed is still unresolved. All investors save with a view of investing in future for better returns. While it is believed that bonds offer returns but less risky, they generally still don't attract much euphoria like stocks. And therefore, it's still a puzzle if stocks and bonds compete or complement each other on the same market.

\subsection{Stocks \& Forex}

The conventional belief is that strong equity markets are accompanied by currency appreciation. Equally, the same conventional $n$ knowledge is that, when share prices rise, investors gain confidence in the country economic and investment growth or recovery in situation where it had gone flopped. This in turn could foster foreign investors to trickle in and hence bring more inflow of foreign funds. These foreign funds will lead to a higher demand for local currency to enable transactions in local the capital markets. A higher demand for local currency means appreciation of the currency value. On the contrary, when the stock prices tumble, investor confidence wear off, leading to withdrawal or selling of shares and convert back their cash to foreign currencies to a higher demand for foreign currency hence their appreciation.

Much of those who support the view above base their arguments on demand and supply. However, other factors have not been considered. For example, the effect of hedging and monetary policy which affects foreign exchange reserves and stock market could play a part in the transmission mechanism between stocks and foreign exchange. Therefore, if the effect of other macroeconomic factors and other factors are included in the equation then the direction of correction could either positive or negative. Studies done in this area include: Andreou et al., [10];Gulati \& Kakhani [11]; Hau \& Rey [12] and Kisaka \& Mwasaru [13].

\subsection{Bonds \& Forex}

A bond is a debt instrument in which a company or government uses to borrow funds from the public. The public or corporate who buy bonds are also known as investors. Bond are usually placed for a period of time at a varying or fixed interest rate. Bonds are used by companies and governments to raise money and finance a variety of projects and activities. Most of these projects are usually heavy capital cost projects like infrastructure. Two common terms used in bond markets are Bond Yields and Bond Prices. The bond price refers to the cost of the bond that is what the investor pays to buy the bond. Bond yield is the interest that the Investor is paid by the bond issuer (Corporate or government) for the money invested. Usually the Bond yield and Bond price have an inverse relationship. The common element between foreign exchange markets and bond markets is the monetary policy proxied by interest rates. Specific countries interest rates in the market usually provides the bond yield benchmark. Interest rates in turn is affected by affects inflation and vice versa. Increase in consumer Index (Prices) leads to inflation and this in effect leads to the possibility of interest rate increases as government regulates money supply. This action in turn leads to higher bond yields. If the bond market is concentrated with foreign investors, then higher bond yields in the bond market will lead to higher demand for the local currency as foreign investors exchange their currency for the local currency to participate in the bond market within that country. Studies that researched in this area include, Lace et al. [14] and Ciner et al. [15].

\subsection{Problem Statement}

According to the Market Microstructure theory, market microstructure is the process and outcomes of exchanging assets under certain trading rules including the role of information in the price discovery process, the definition, measurement, control, and determinants of liquidity and transactions costs, and their implications for the market efficiency. Stock, bond and currency are among the key assets in the financial markets heavily traded. These Three markets play a significant role not only in the financial sector but the entire economy country specific or even worldwide due to their influence on other asset prices like mortgages, loans and commodities.

However, these three financial markets do not trade in isolation and hence there should be some degree of correlations and co-movements. Few studies have been carried to investigate these inter-linkages and only concentrated on two markets at time. These studies have investigated stocks and currency and/or stocks and bonds. Very few studies have combined all the three markets in one study like Ciner et al. [15]. Other studies in this area have concentrated causality and not volatility movements between markets. In response to this problem, our study aspires to investigate these market microstructure linkages and in addition investigate the effect of monetary policy on each market in Kenya as proxy for emerging countries. The study plans to carry out an asymmetric volatility study between the markets to establish the market intermarket correlations and volatility spillovers between any 
two markets ant any given time. The researcher will use this analysis to propose appropriate policy interventions.

\subsection{Study Objectives}

The General objective is to discuss and investigate the market microstructure Linkages between stocks, bonds and Foreign exchange markets in Kenya

\subsection{Value of the Study}

(i) To contribute to the existing literature on Market microstructure and market interactions. Since this is an area that has great potential of further growth and will attract further academic research by providing reference materials for future researchers.

(ii) Market players in the Kenyan Financial Sector will also get a footing on how these markets inter-link hence make better investment decisions and assist in asset pricing and movements.

(iii) Policy makers in the Kenyan Financial Sector will also get a footing on how monetary policy affects these three markets linkages and hence address them to enhance growth.

\section{Literature Review}

\subsection{Theoretical Review}

Market microstructure Theory deals with how trading and details of exchange occurs in financial markets. This theory further expounds on exchange of real or financial assets. Market Microstructure main area of study involves the processes and determinants of market performance. This includes, market structures, investor preferences, transactional costs, price changes (discovery and formation) and information disclosure, trading volumes and trading behaviors. Market Microstructure is the study of the process and outcomes of exchanging assets under explicit trading rules. While much of economics abstracts from the mechanics of trading, microstructure literature analyzes how specific trading mechanisms affect the price formation process O’Hara [16].

Arbitrage pricing theory was developed by Roll and Ross in 1976 as an alternative to CAPM which had some deficiencies. Roll \& Ross [17]. With APT returns can be generated by more than one factor. These factors can include changes in macroeconomic conditions and market surprises. Some of the macroeconomic factors include inflation, yield spread, interest rates and industrial production. All changes in these factors are unanticipated meaning that asset prices will always reflect all known information about the economy. This theory comes in handy to this study since the returns of these three markets will be under investigation. Stocks and bonds returns are affected by volatilities of interest rates and foreign exchange markets.

\subsection{Empirical Review}

Jammazi et al. [1] examined the dynamic interactions between stock and long-term government bond markets for several countries. The authors used time-varying DCCGARCH-copula approach. The results showed that there was a positive interlink between stock and bond returns in the 1990s. This was alluded to due to inflation. However, their existed a negative relationship between stock and government bond markets since the early 2000s which was attributed to the flight-to-quality phenomenon. There was a positive stock-bond link from 2009 after the emergence sovereign debt crisis in late 2009.

Andersson et al. [2] examined the impact of macroeconomic expectations and perceived stock market uncertainty on the correlation between stock and bond returns. The research employed DCC-GARCH model with data spanning January 1991 to August 2006 for the United States and from January 1992 to August 2006 for the United Kingdom and Germany. Results indicated that stock and bond prices tend to move in the same direction during periods of high inflation expectations and moved in the opposite direction during periods with the lowest levels of inflation expectations.

$\mathrm{Li}$ and Zou [3] investigated the correlation of China's T-bond and stock returns given policy and information shocks using DCC-GARCH model. The researchers found that the bond-stock correlations respond more strongly to joint negative than joint positive shocks. They attributed this to fact that during times of bad news for both assets, investors tend to move both the T-bond and stock prices in the same direction, but tend to shift funds from one asset class to the other when hit concurrently by good news.

Ali \& Joher [4] examined the correlation structure, cointegration relationship and volatility linkage between stock and bond market indices from January 1994 to June 2004. The authors used Johansen Cointegration test, VECM-X model and GARCH $(1,1)$ test the existence of long-term relation and volatility linkage between stock and bond market. Their results showed the existence of mean-reverting pattern of correlation across different economic environments. Findings on interlinkages of stock and bond indices showed existence of equilibrium relationship in the short run. And there was evidence conditional volatility between the bonds and stock market.

Rankin \& Idil [5] studied the correlation between movements in equity prices and bond yields using data from 1986 to 2014 divided into two regimes of 1986 to 1999 and 2000 to 2014. Results indicated there is a positive correlation between stock and bond yield for an extended period over the past 15 years in the 19th century. On the other hand, there was a negative correlation observed throughout much of the 20th century and this was alluded shifts in US monetary policy regimes which reduced stock-bond yield correlations. This clearly indicates that monetary policy regimes play an important role not only in one market but the effect spills over to other markets. Therefore, such policies should be underpinned and geared towards economic developments.

Skintzi [8] investigated the dynamics of the interlinkages between stock and bond market returns in the Eurozone. Using time-varying patterns, the author employed Bayesian Model Averaging (BMA) data period from second quarter of 1992 to second quarter of 2015. Results demonstrated that stock-bond market co-movement in European countries considerably changed with time and exhibited an increase due to the recent sovereign debt 
crisis. Other factors like inflation and interest rates also affected the stock-bond interlink.

Andreou et al. [10] investigated a bi-directional linkage between the stock and foreign exchange markets of twelve emerging economies in Asia using weekly observations covering the period January1989- to August 2008(1024 observations). The authors employed a quarto-variate VAR-GARCH model with the BEKK representation. The study found that there is strong evidence of bidirectional causality in variance between the foreign exchange market and stock market in all emerging economies but Colombia

Gulati and Kakhani [11] investigated the Relationship Between Stock Market and Foreign Exchange Market in India. The study utilized the Granger Causality test and Correlation Method to establish the relationship between Stock indices and foreign exchange rate. The authors found that there was no significant relationship between stock prices and exchange rates.

Hau and Rey [12] developed an integrated analysis of Exchange rates, equity prices, and capital flows for 17 OECD countries vis-a'-vis the United States. There results found out that large degree of exchange rate volatility is explained by sufficient elasticity of forex liquidity supply. The authors also found that there was a negative correlation between foreign equity excess returns (in local currency) and the corresponding exchange rate returns. Lastly, they found a significant positive correlation between exchange rate returns and net equity flows.

Kisaka and Mwasaru [13] examined the causal relationship between foreign exchange rates and stock prices in Kenya from November 1993 to May 1999. The researchers employed monthly observations the Nairobi Securities Exchange price index and the nominal Kenya shillings per US dollar exchange rates. The study findings showed that Foreign exchange rates Granger-causes stock prices in Kenya. They concluded that, there is unidirectional causality from exchange rates to stock prices.

Lace et al., [14] analyzed the determination of the EUR/USD exchange rate with U.S. and German government bond yields in the post-crisis period using linear regression. Results from the study indicated bond yields only determined $5.3 \%$ of the exchange rate fluctuations by the change in the 2-year U.S. government debt yields. The further found that an increase in the shorter-term bond yield leads to a depreciation of the currency in which the fixed income security is denominated, while the increase in the yield of long term (10-year) securities lead to an appreciation of the currency in which they are denominated.

Ciner et al. [15] investigated the dynamic correlations between stocks, bonds, gold, oil and exchange rates using DCC-GARCH model. The author used daily data for the period between January of 1990 and June of 2010. The study results showed two parallels between the two countries used in the research. In the US, Bond returns were positive when there are extreme declines in equities. There was also a positive correlation between bond returns and extreme dollar declines. On the other hand, in the UK, bonds provided a haven role against equities in the UK. British pound can be regarded as a haven against extreme declines in equities and bonds. The authors attributed this to the fact that the role played by the British currency in financial markets is very different than the role played by the US dollar regarding extreme movements.
Bansal and Shaliastovich [18] analyzed asset price puzzles in bond, currency and equity markets four countries (United Kingdom, Germany, Japan and United States using data from January 1976 (July 1978 for Japan) to November 2005. The authors employed vector autoregressive model (VAR). The study findings showed that when forward premium decreases the domestic currency depreciated. They also found out that positive shock to consumption volatility move the expected excess bond returns and the yield-spread in the same direction.

Kal et al. [19] studied the Dynamic Relationship of Bond Markets, Stock Markets and Exchange Rates. The authors used quarterly observations of four bilateral nominal exchange rates (price of the US dollar in terms of each currency): the Australian dollar (AUD), the Canadian dollar (CAD), the Japanese Yen (JPY), and the British Pound (GBP). The study employed Markov-Switching Vector Autoregressive Model (MS-VAR) and their results showed that the interrelationship between these financial/economic variables vary based on regimes in the model. That is over-valuation (regime 1) or undervaluation (regime 2). They also found out that the effect of the stock market yield differential had a varying effect on foreign exchange rates which were statistical significant between the states/regimes.

Ingalhalli and Reddy [20] analyzed the causal relationship between oil, gold, exchange rate and stock market in India. By employing the Correlation Matrix and Granger causality test methods, the findings revealed that stock price index had a positive relationship with exchange rate. They attributed this to the case of stock price index attracting more Foreign Direct Investments (FDI) into the economy and hence creating more demand for local currency.

\section{Data and Methodology}

\subsection{Introduction}

Our data consist of monthly observations and cover the period between January of 2012 and September 2017. The study data and include variables to represent equity, bond and currency market rates. Equities are represented by NSE 20-share Index and the bonds are represented by the bond turnover. The currency markets are represented by the central bank of Kenya (CBK) US-KES exchange rates as a measure of foreign exchange influence on other markets. Commercial Banks Weighted Average Lending Rates will be used as a measure of monetary policy transmission to each market. Equity and Bonds data will be collected from Nairobi Securities Exchange while currency data and Lending rates will be collected from the Central bank of Kenya website. A graphical representation and summary statistics of the data will also be provided. This will mainly be used to check trend and shape of the data.

\subsection{Dynamic Condition Correlation EGARCH (DCC-EGARCH)}

According to Tsay [21] the autoregressive conditional heteroscedastic (ARCH) the generalized ARCH (GARCH), exponential GARCH (EGARCH) are the most common utilized volatility models This study will employ 
the DCC-EGARCH. The DCC-GARCH model was proposed by Engle and Sheppard (2001) and Engle (2002) to estimate large time-varying covariance matrices. EGARCH is used to assist in capturing both positive and negative shocks of equal force which asymmetrically contribute to volatility. This model combines dynamic correlation and the GARCH model, and hence it can deal with heteroscedasticity and large dynamic covariance matrices.

GARCH-DCC is a twostep model where which uses univariate equation to generalize for the multivariate GARCH-DCC model. The first step accounts for the conditional heteroscedasticity. It consists of estimating for each one of the series of returns and its conditional volatility using a GARCH model. The second step captures dynamics in the correlation.

\subsection{Computation of Return Series}

The natural logarithm of the simple gross return of an asset is called the continuously compounded return Tsay [21]. Continuously, each compounded monthly return of each series of each market is generated as follows;

$$
r_{t}=\ln \left(1+R_{t}\right)=\ln \left(\frac{P_{t}}{P_{t-1}}\right)=P_{t}-P_{t-1}
$$

Where $p_{t}=\ln \left(P_{t}\right)$. Continuously compounded returns $r_{t}$ enjoy some advantages over the simple net returns $R_{t}$. First is that, continuously compounded multi-period return is simply the sum of continuously compounded one-period returns involved. Second, statistical properties of $\log$ returns are more tractable.

\subsection{MODEL Estimation}

Consider a multivariate return series $r_{t}$ denoted by;

$$
r_{t}=\mu_{t}+a_{t}
$$

Where $\mu_{t}=E\left(r_{t} \mid F_{t-1}\right)$ is the conditional expectation of $r_{t}$ given the past information $F_{t-1}$, $\mu$ is commonly known as the mean equation. The second part $a_{t}=\left(a_{1 t}, \cdots a_{k t}\right)$ is the shock, or innovation, of the series at time t.

We can therefore estimate GARCH $(p, q)$ model as follows:

$$
a_{t}=\sigma_{t} \varepsilon_{t}, \sigma_{t}^{2}=a_{0}+\sum_{i=1}^{p} a_{i} a_{t-1}^{2}+\sum_{j=1}^{q} \beta_{i \sigma_{t-1}^{2}}
$$

Where $\varepsilon$ is a sequence of identically and independently distributed (iid) random variable with mean 0 and variance 1, $\alpha_{0}>0, \alpha_{1} \geq 0$, and $\sum_{i=1}^{\max (p, q)}\left(\alpha_{i}+\beta_{i}\right)<1$. It is expected that $\alpha_{1}=0$ for $i>p$ and $\beta_{j}=0$ for $j>q$. The equation (3) reduces to ARCH (p) model when $q=0$. The $\alpha_{i}$ and $\beta_{j}$ are ARCH and GARCH parameters respectively.

The E-GARCH $(p, q)$ model is given by:

$$
\ln \left(\sigma_{t}^{2}\right)=\alpha_{0}+\sum_{i=1}^{p} \alpha_{i} \frac{\left|a_{t-1}\right|+\gamma a_{t-1}}{\sigma_{t-1}}+\sum_{j=1}^{q} \beta_{i} \ln \left(\sigma_{t-j}^{2}\right)
$$

Where $\varepsilon_{t-1}=\frac{a_{t-1}}{a_{t-1}}$ are the error terms at lag 1. $a_{t-1}$ is the white noise at lag 1 and contributes to $\alpha_{i}\left(1+\gamma_{i}\right)\left|\varepsilon_{t-i}\right|$ the $\log$ volatility. Negative $\alpha_{t-1}$ gives $\alpha_{i}\left(1-\gamma_{i}\right)\left|\varepsilon_{t-i}\right|$, where $\varepsilon_{t-1}=\frac{a_{t-i}}{\sigma_{t-i}}$. The parameter $\gamma_{i}$ signifies the leverage effect of $a_{t-i}$ and is assumed to be negative in real application

\subsection{The DCC-GARCH estimation}

Considering $\mathrm{k}$ asset returns and a variance covariance matrix $H_{t}$, then

$$
r_{t} \mid F_{t-1}=N\left(0, H_{t}\right)
$$

And Conditional variance of DCC is given by

$$
H_{t} D_{t} R_{t} D_{t}
$$

Where $R_{t}$ is the time varying correlation matrix and $D_{t}$ is the $k \times k$ diagonal matrix from the consisting of the conditional standard deviations of elements of $a_{t}$. The loglikelihood of the estimator is given by;

$$
\begin{gathered}
L=\frac{1}{2} \sum_{t=1}^{T}\left(k \log (2 \pi)+\log \left(\left|H_{t}\right|\right)\right)+r^{\prime} H_{t}^{-1} r_{t} \\
=\frac{1}{2} \sum_{t=1}^{T}\left(k \log (2 \pi)+\log \left(\left|D_{t} R_{t} D_{t}\right|\right)+r^{\prime} D_{t}^{-1} R_{t} D_{t}^{-1}\right) \\
=\frac{1}{2} \sum_{t=1}^{T}\left(\begin{array}{l}
k \log (2 \pi)+2 \log \left(\left|D_{t}\right|\right) \\
+\log \left(\left|R_{t}\right|\right)+\varepsilon^{\prime} R_{t}^{-1} \varepsilon_{t}^{-1}
\end{array}\right)
\end{gathered}
$$

Where $\varepsilon_{t} \sim N\left(0, R_{t}\right)$ are residuals of a univariate GARCH.

We shall use the above univariate equation to generalize for the multivariate GARCH-DCC model. The GARCH-DCC involves two steps. The first step accounts for the conditional heteroscedasticity. It consists in estimating for each one of the $\mathbf{k}$ series of returns $r_{t}$, its conditional volatility $\sigma_{t}$ using a GARCH model. The second step is where the correlation dynamics are captured.

\section{Results and Discussion}

\subsection{Results and Discussion}

First, we discuss the nature of our data. Figure 1 shows the time series plot for NSE 20Share Index, Bonds turnover and Foreign exchange rates (KES/USD), from January 2004 to June 2017. The data plots exhibit continuous upwards trend with fluctuations. The movements of the plots indicate that the mean and the variance of the markets data are changing overtime. This implies that the mean is non-constant and the variance is unstable. 


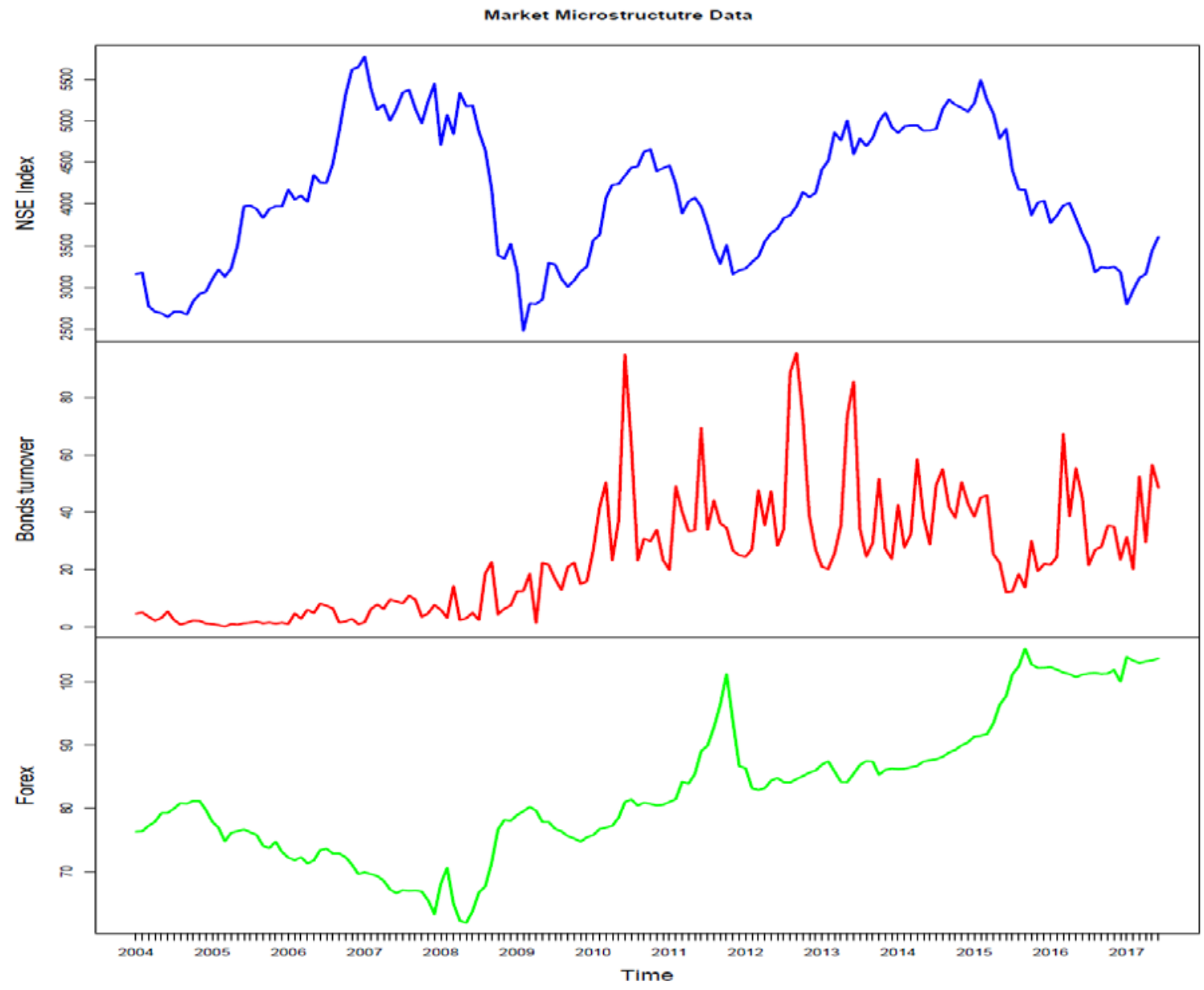

Figure 1. Plots of Market Data

\subsection{Descriptive Statistics}

From sample 162 observation descriptive statistics as presented in Table 1 indicated that returns of the variables in the study are not normal as indicated by the Jarqueberra tests.

Skewness of Stocks and Foreign exchange is negative and positive for Bond market (The skewness of the normal distribution or any perfectly symmetric distribution is zero). The Kurtosis signify that the distributions of the returns are Fat-tailed.

Table 1. Market Returns Descriptive Statistics:

\begin{tabular}{|c|c|c|c|}
\hline Statistics & Stocks & Bonds & Forex \\
\hline Mean & 0.00 & 0.01 & 0.000 \\
\hline Maximum & 0.14 & 2.79 & 0.07 \\
\hline Minimum & -0.26 & -2.60 & -0.08 \\
\hline Std. Dev & 0.06 & 0.66 & 0.02 \\
\hline Skewness & -0.96 & 0.19 & -0.44 \\
\hline Kurtosis & 2.93 & 3.57 & 4.64 \\
\hline J-B Statistics & $85.83(0.0)$ & $90.34(0.0)$ & $155.56(0.0)$ \\
\hline
\end{tabular}

Significant Level for J-B Statistic is 5\% Level

\subsection{Stationarity/Unit Root Test}

This research employs the unit root tests of ADF to determine the Stationarity (stability) of the time series data. The results indicate that NSE share index return, bonds turnover returns and Foreign Exchange Returns do not have the unit root characteristic. This means the returns of our data from our three markets are stationary time series data, under 5\% significance level.

Table 2. Augmented Dickey-Fuller stationarity tests

\begin{tabular}{|c|c|c|c|}
\hline ADF & Stocks & Bonds & Forex \\
\hline Statistic & -8.021 & -13.30 & -8.69 \\
\hline Critical value(Tau2) & -3.46 & -3.46 & -3.46 \\
\hline
\end{tabular}

Significant Level for ADF Statistic is 5\% Level

Figure 2, shows that compounded returns plots which appear and confirm stationarity of the returns. The NSE-share index return volatility, Loans rate return volatility, Premiums return Volatility and the Interest rate return volatility shows the clustering phenomenon as noted as Mandelbrot (1963) where large changes tend to be followed by large changes, of either sign, and small changes tend to be followed by small changes. This indicates that Stock, bond and foreign exchange returns are not independent across time and this exhibit the autocorrelation features in squared and absolute returns or even in residuals of the series data. This also could also be evidence of heteroscedasticity in the returns. Most evidently is Volatility clustering appearing in some specific periods like 2005, 2008, 2012 and 2017. This can be attributed to the political uncertainties in Kenya as this are the years which followed first constitution amendment referendum, and the subsequent years were due to general elections. However, we note that there were no high volatilities clustering in 2013 since most of the uncertainties had be captured in 2012 . 


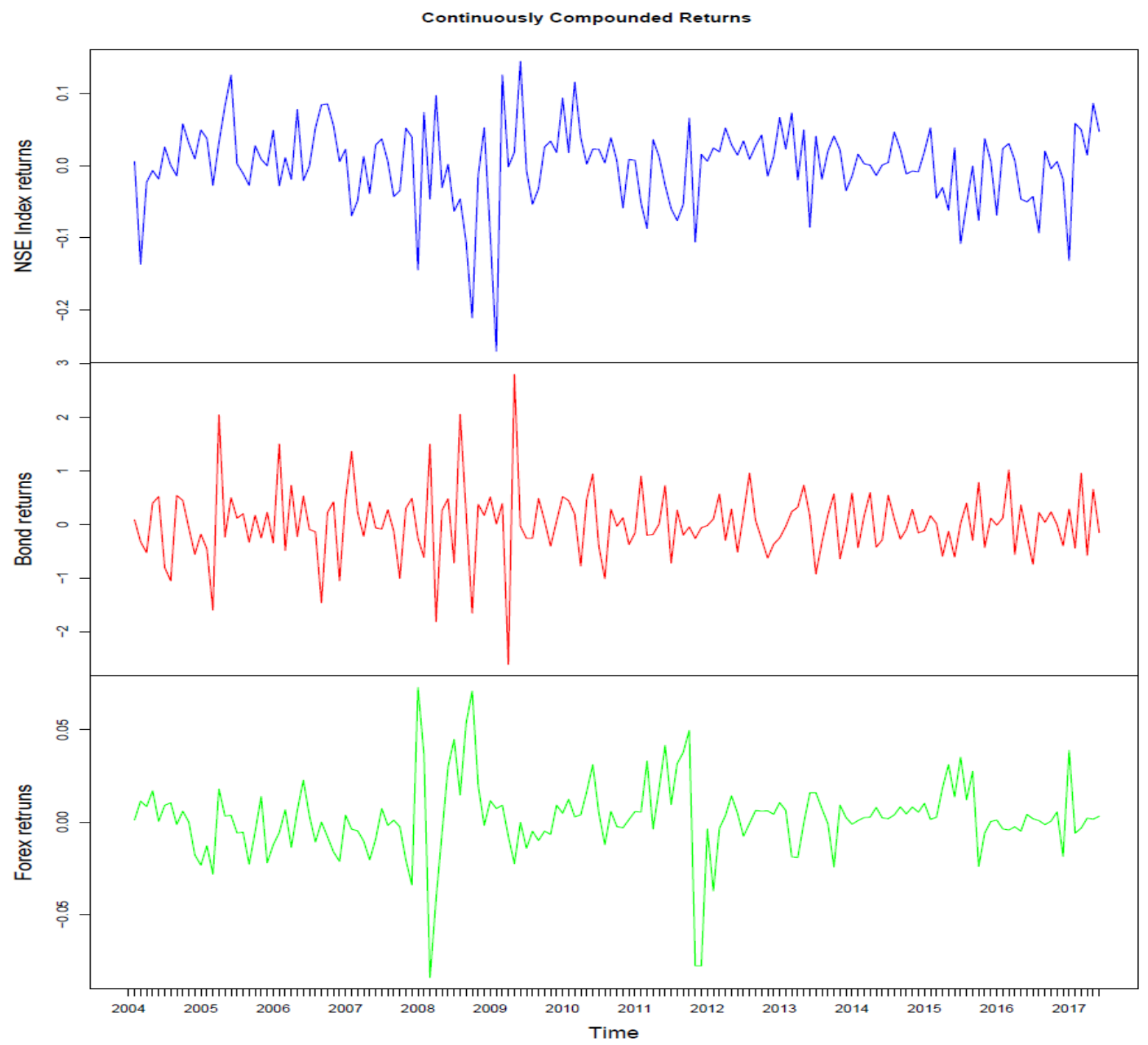

Figure 2. Plots of Data returns

\subsection{Unconditional Correlations}

Table 3 indicates that, there is an insignificant positive correlation equities and bonds at 5 percent level of significance. However, we see that there is a negative and significant correlation between share prices and foreign exchange rate markets. Finally, we see that Foreign exchange there is a negative but insignificant correlation between Bonds and Foreign exchange rates.

Table 3. Unconditional correlations:

\begin{tabular}{|c|c|c|c|}
\hline Test & Stocks & Bonds & Forex \\
\hline Stocks & 1 & & \\
\hline Bonds & $0.07(0.945)$ & 1 & \\
\hline Forex & $-3.220(0.005)$ & $-0.90(0.37)$ & 1 \\
\hline
\end{tabular}

Authors calculations.

\subsection{ARCH Effect Test}

To use an ARCH/GARCH model or any of its GARCH family series, the residuals of that series need to be tested for conditional heteroscedasticity (Presence of ARCH effects). This paper employs, the ARCH Lagrange Multiplier (ARCH LM) and Box-Ljung tests are employed for this process to test the conditionally heteroscedasticity. The results are displayed in Table 4 . The results of the ARCH effect test indicate that the data from our three markets have the conditionally heteroscedasticity. This means that we can employ GARCH model to analyze our market linkages.

Table 4. Descriptive Statistics:

\begin{tabular}{|c|c|c|c|}
\hline Test & Stocks & Bonds & Forex \\
\hline LM Test & $48.24(0.00)$ & $35.94(0.04)$ & $86.45(0.00)$ \\
\hline Box-Ljung test & $48.07(0.00)$ & $36.09(0.04)$ & $79.49(0.00)$ \\
\hline
\end{tabular}

Significant Level for ADF Statistic is 5\% Level

\subsection{Rolling Correlations and Covariances}

Before choosing which model of GARCH family the study will employ. Rolling Correlations and Rolling Covariance was tested. The main reason for this was to the relationship between any two market returns over time. Figure 3 and Figure 4 shows that the correlations just like the variance are not constant over time as evidenced by the 20-month window estimates over the time duration. So, the DCC is a better candidate to model the data. 


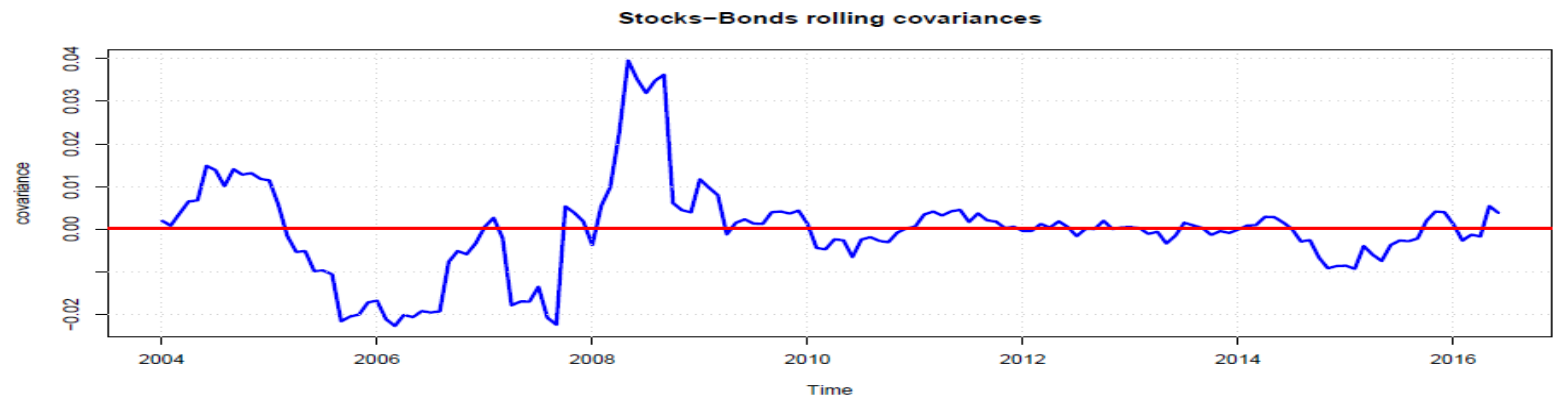

Stocks-Forex rolling covariances
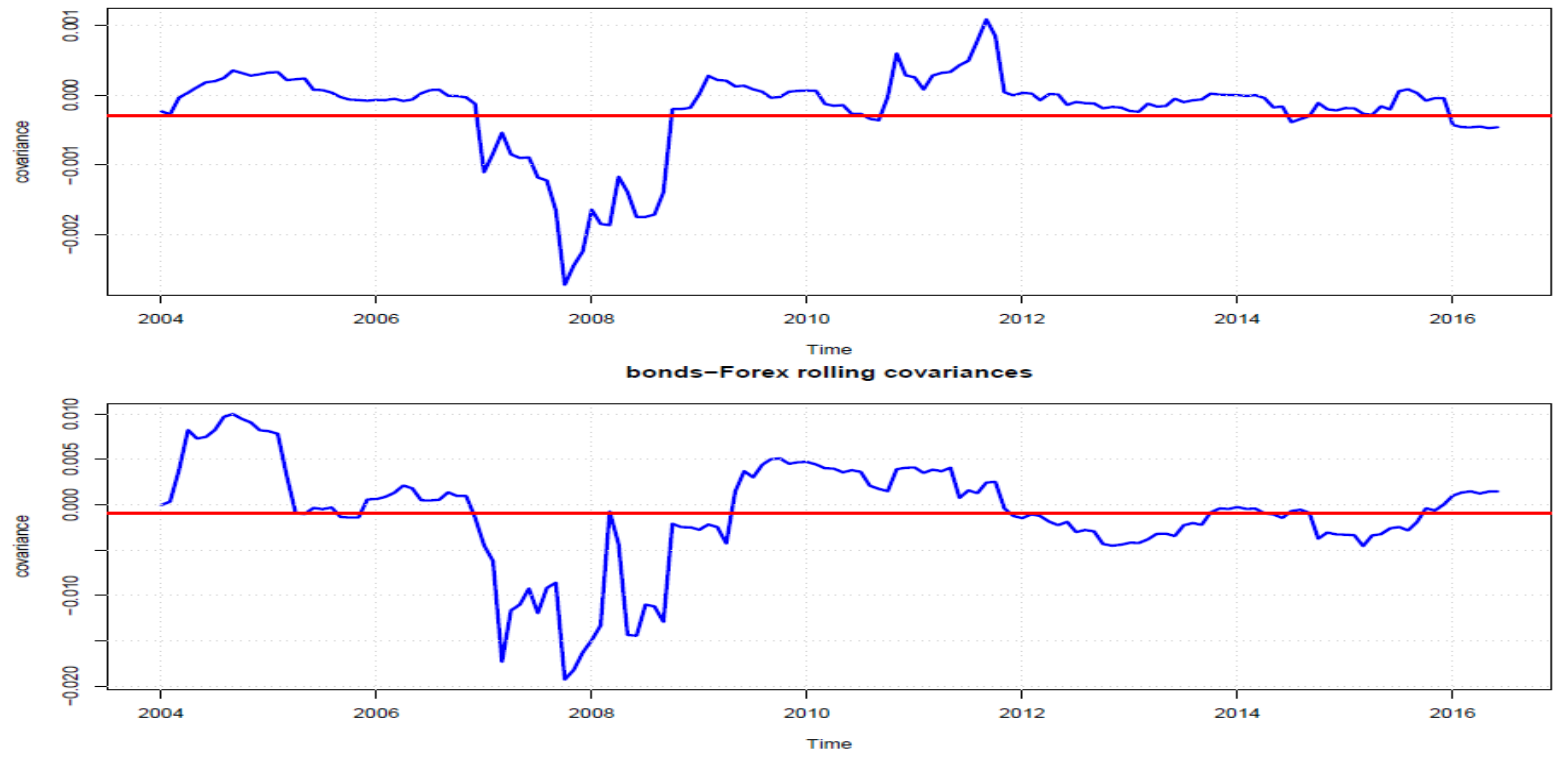

Figure 3. Rolling Covariances
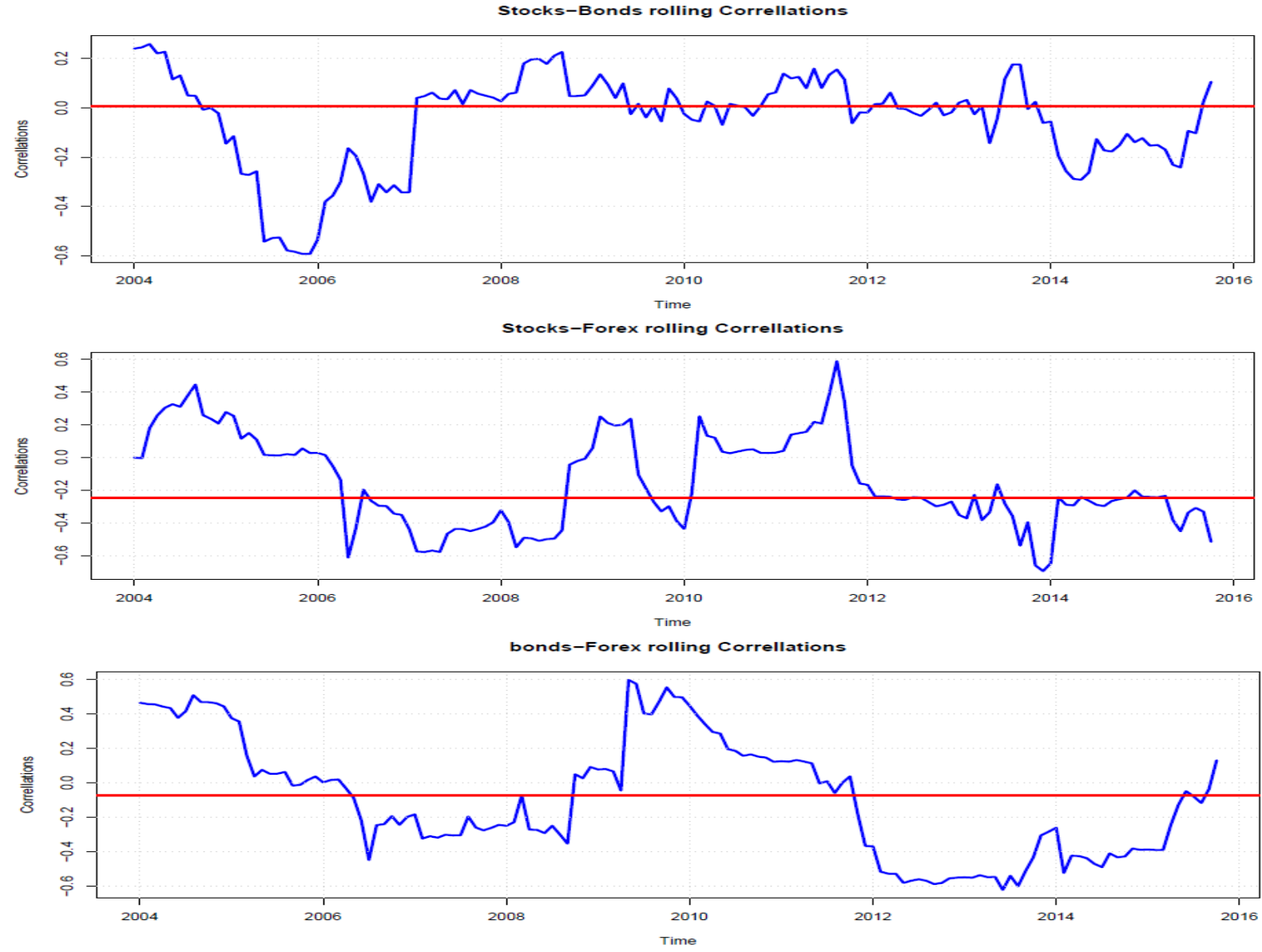

Figure 4. Rolling Correlations 


\subsection{Univariate GARCH Models}

To analyze the bivariate linkages between markets, respective returns are first fitted with univariate exponential GARCH (EGARCH) then aDCC is fitted in the second step. The following provided optimal fitting

a) NSE-20 share index: ARMA $(0,0)-G A R C H(1,2)$.

b) Bonds returns: ARMA (2,2)-EGARCH $(1,1)$.

c) Foreign exchange rate: ARMA $(0,1)-\operatorname{GARCH}(1,2)$

Therefore,

\section{Mean Models will be given by}

(i) Stocks: $X_{t}=\mu+\varepsilon_{t}$

(ii) Bonds: $\begin{aligned} X_{t}= & \mu+\phi_{1} X_{t-1}+\phi_{2} X_{t-2} \\ & +\varepsilon_{t}+\theta_{1} \varepsilon_{t-1}+\theta_{2} \varepsilon_{t-2}\end{aligned}$

(iii) Forex: $X_{t}=\mu+\varepsilon_{t}+\theta_{1} \varepsilon_{t-1}$

And

\section{Variance Models will be given by}

(i) Stocks:

$$
a_{t}=\sigma_{t} \varepsilon_{t}, \sigma_{t}^{2}=\alpha_{0}+\alpha_{1} a_{t-1}^{2}+\beta_{1} \sigma_{t-1}+\beta_{1} \sigma_{t-1}
$$

(ii) Bonds:

$$
\ln \left(\sigma_{t}^{2}\right)=\alpha_{0}+\alpha_{1} \frac{\left|a_{t-1}\right|}{\sigma_{t-1}}+\gamma \frac{a_{t-1}}{\sigma_{t-1}}+\beta_{1} \ln \left(\sigma_{t-j}^{2}\right)
$$

(iii) Forex:

$$
a_{t}=\sigma_{t} \varepsilon_{t}, \sigma_{t}^{2}=\alpha_{0}+\alpha_{1} a_{t-1}^{2}+\beta_{1} \sigma_{t-1}+\beta_{2} \sigma_{t-2}
$$

Figures 5 through 7 show the corresponding conditional volatility for each market.

\subsection{Conditional Volatility}

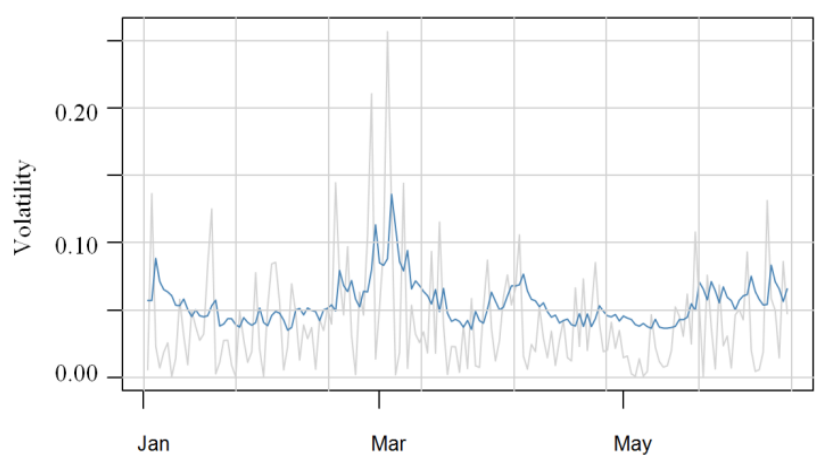

Figure 5. Share Index Conditional Volatility

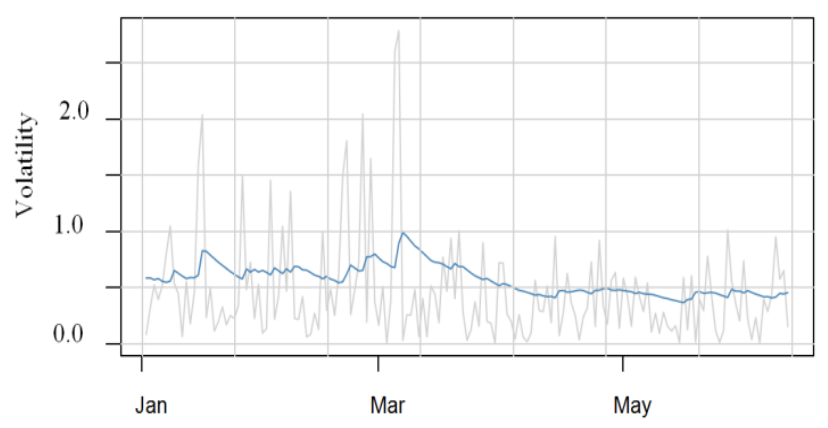

Figure 6. Bonds Conditional Volatility

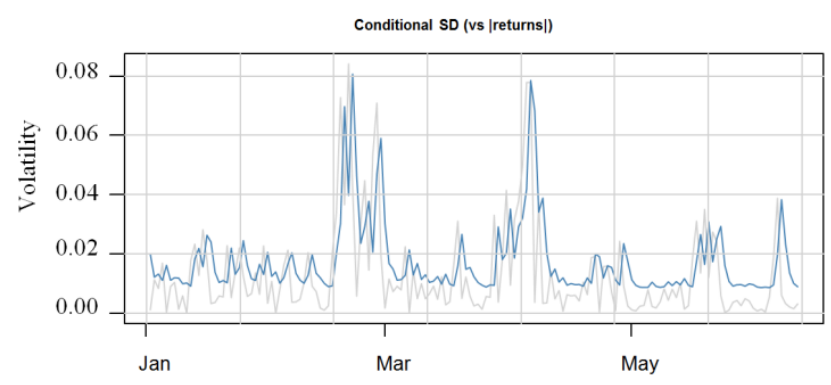

Figure 7. Forex Conditional Volatility

\subsection{Asymmetric DCC}

\subsubsection{Stocks and Bonds}

Table 5 represents the result of Stocks and Bonds aDCC GARCH model fit parameters estimation. The parameters estimates for aDCC-GARCH $(1,1)$ model for stock markets and Bonds show the $\alpha_{1}$ value of the shortrun persistence is positive and $\beta_{1}$ of $92 \%$ of conditional correlation value depends on its previous one. The sum of the DCC $(1,1)$ parameters are less than one which implies that the model is strictly mean reverting. The dynamic parameter is is zero and insignificant meaning that there is no feed-back volatility correlation effect among variables.

Table 5. Stocks-Bonds aDCC Model Fit

\begin{tabular}{ccccc}
\hline Parameter & Estimate & Std.Error & t Value & $\operatorname{Pr}(>\mid \mathrm{t})$ \\
\hline$\alpha$ & 0.006 & 0.001 & 0.0145 & 0.988 \\
\hline$\beta$ & 0.924 & 6.879 & 0.1343 & 0.893 \\
\hline
\end{tabular}

Source: Author's calculations.

\subsubsection{Stocks and Foreign Exchange}

The resulting Table 6 of NSE 20-share index returns and foreign exchange aDCC-GARCH the parameters estimates for aDCC-GARCH $(1,1)$ model for stock markets and Foreign exchange show the $\alpha$ value of the short-run persistence is positive and $\beta$ of zero implying that conditional correlation value does not depend on its previous values. The sum of the DCC $(1,1)$ parameters are less than one which implies that the model is strictly mean reverting.

Table 6. Stocks-Forex aDCC Model Fit

\begin{tabular}{ccccc}
\hline Parameter & Estimate & Std.Error & t Value & $\operatorname{Pr}(>\mid \mathrm{t})$ \\
\hline$\alpha$ & 0.402 & 0.133 & 3.026 & 0.002 \\
\hline$\beta$ & 0.000 & 0.000 & 0.0145 & 0.988 \\
\hline
\end{tabular}

Source: Author's calculations.

\subsubsection{Bond Market and Foreign Exchange}

Table 7 shows results of Bond Market and Foreign exchange aDCC GARCH model fit estimation. Just like prior bivariate linkages above, significant part of the conditional correlation value persists from its first lag (about 68\%).

The parameters estimates for aDCC-GARCH $(1,1)$ model for stock markets and Foreign exchange show the $\alpha_{1}$ value of the short-run persistence is positive and $\beta_{1}$ of 
zero implying that conditional correlation value does not depend on its previous values. The sum of the DCC $(1,1)$ parameters are less than one which implies that the model is strictly mean reverting.

Table 7. Bonds-Forex aDCC Model Fit

\begin{tabular}{ccccc}
\hline Parameter & Estimate & Std.Error & $\mathrm{t}$-value & $\operatorname{Pr}(>\mid \mathrm{t})$ \\
\hline$\alpha$ & 0.323 & 0.118 & 2.745 & 0.006 \\
\hline$\beta$ & 0.676 & 0.274 & 2.470 & 0.0135 \\
\hline
\end{tabular}

Source: Author's calculations.

The asymmetric DCC empirical results show that for any given Bivariate set, there is a positive asymmetric volatility effect. This means that any the markets tend to respond more on negative news than good news in the market. Our findings reveal a positive conditional correlation for any given bivariate. This means that Kenya investors move stocks and bonds in the same direction and do not necessarily subscribe to the philosophy of "flight-forsafety". These findings could also signal the possibility of Kenyan investors still having low interest in the bonds market and only invest in the bond market as a second option and not as an alternative. The same is also revealed in the unconditional correlation between stocks and bonds.

These results could also imply the bond market being dominated by foreign exchange considering the high correlation of about $68 \%$ between bonds market and foreign exchange market as compared to co correlation between foreign exchange and stocks.

\section{Conclusion}

This study examined the market microstructure linkages between stocks, bonds and foreign exchange using asymmetric dynamic conditional correlation (aDCC). Monthly market returns of Nairobi securities exchange 20 share index, bonds, and foreign exchange from January 2004 to December 2016. Exponential Generalized Autoregressive Correlation Heteroskedastic (EGARCH) model was used in the aDCC in order to capture both negative and positive shocks and volatilities in the financial market.

The study found that, there is an existence time varying variance correlation between any bivariate set in the three markets in Kenya. The conditional correlations are positive. However, the unconditional correlation reveal, a negative correlation between Foreign exchange markets and the Bonds as well as stocks. Our conditional correlation results agree with most of other previous results in the literature.

The study proposes policy makers like the government through treasury, capital markets authority (CMA) and Nairobi Securities Exchange (NSE) to encourage more Kenyan investors to invest in bond market by marketing the bond market through educational forums, conferences. The authorities should also stabilize the Kenyan currency so as to stabilize the bond market considering they move in the same direction.

\section{Acknowledgements}

We acknowledge Tina Muriuki from the United Nations Office at Nairobi (UNON), Budget Section for her great passion and effort in reviewing, commenting and correcting the grammatical errors. Her inputs are greatly appreciated.

\section{References}

[1] Jammazi, R., Tiwari, A. K., Ferrer, R., \& Moya, P. (2015). Timevarying dependence between stock and government bond returns: International evidence with dynamic copulas. The North American Journal of Economics and Finance, 33, 74-93.

[2] Andersson, M., Krylova, E., \& Vahamaa, S. (2008). Why does the correlation between stock and bond returns vary over time?. Applied Financial Economics, 18(2), 139-151.

[3] Li, Xiao-Ming and Li-Ping Zou. 2008. How Do Policy and Information Shocks Impact Comovements of China's T-bond and Stock Markets? Journal of Banking and Finance 32: 347-359.

[4] Ahmed, Ali and Huson Joher. 2009. The Equilibrium Relations between Stock Index and Bond Index: Evidence from Bursa Malaysia. International research journal of finance and economics 30: 7-17.

[5] Rankin, E., \& Idil, M. S. (2014). A century of stock-bond correlations. RBA Bulletin, 67-74.

[6] Fan, J., \& Mitchell, M. Equity-Bond correlation: A Historical Perspective. Accessed on 29 October 2017 from https://www.grahamcapital.com/library.aspx.

[7] The CMA Quarterly Capital Markets Statistical Bulletin Q1.2017.

[8] Skintzi, V. (2017). Determinants of stock-bond market comovement in the Eurozone under model uncertainty.

[9] The CMA Quarterly Capital Markets Statistical Bulletin Q3.2017

[10] Andreou, E., Matsi, M., \& Savvides, A. (2013). Stock and foreign exchange market linkages in emerging economies. Journal of International Financial Markets, Institutions and Money, 27, 248-268.

[11] Gulati, D., \& Kakhani, M. (2012). Relationship between stock market and foreign exchange market in India: An empirical study. Pacific Business Review International, 5(5), 66-71.

[12] Hau, H., \& Rey, H. (2005). Exchange rates, equity prices, and capital flows. The Review of Financial Studies, 19(1), 273-317.

[13] Kisaka, S. E., \& Mwasaru, A. (2012). The causal relationship between exchange rates and stock prices in Kenya Research Journal of Finance and Accounting, 3(7), 121-130.

[14] Lace, N., Macerinskiene, I., \& Balciunas, A. (2015). Determining the EUR/USD exchange rate with US and German government bond yields in the post-crisis period. Intellectual Economics, 9(2), 150-155

[15] Ciner, C., Gurdgiev, C., \& Lucey, B. M. (2013). Hedges and safe havens: An examination of stocks, bonds, gold, oil and exchange rates. International Review of Financial Analysis, 29, 202-211.

[16] O'hara, M. (1995). Market microstructure theory (Vol. 108). Cambridge, MA: Black-well.

[17] Ross, S. (1976), The Arbitrage Theory of Option Pricing, Journal of Economic Theory, Vol 13 no. 3, pp. 341-360.

[18] Bansal, R., \& Shaliastovich, I. (2007). Risk and return in bond, currency and equity markets. Manuscript, Duke University.

[19] Kal, S., Arslaner, F., \& Arslaner, N. (2014). Bond Markets, Stock Markets and Exchange Rates: A Dynamic Relationship (No. 18). Journal of Finance and Accounting, 3(7), 121-130.

[20] Ingalhalli, V., \& Reddy, Y. V. (2016). A Study on Dynamic Relationship between Oil, Gold, Forex and Stock Markets in Indian Context. Paradigm, 20(1), 83-91.

[21] Tsay, R. S. (2010). Analysis of financial time series. Third Edition. John Wiley \& Sons. 